\title{
Rickettsia-like organism associated with tremor disease and mortality of the Chinese mitten crab Eriocheir sinensis
}

\author{
Wen Wang*, Zhifeng Gu \\ College of Biological Sciences, Nanjing Normal University, Nanjing 210097, PR China
}

\begin{abstract}
We report the discovery of a rickettsia-like organism (RLO) in cultured freshwater Chinese mitten crab Eriocheir sinensis. The RLO caused tremor disease and was apparently responsible for a mass mortality (30 to $90 \%$ ) in 2 provinces in southeast China. Moribund crabs were investigated from different districts during outbreaks in 1999 and 2000. With electron microscopy, 3 different pathogens were detected in moribund crabs: a rickettsia-like organism (RLO), virus-like particles (VLP) and a microsporidian-like protozoan (MLP). Based on the high prevalence, infection intensity and cytopathological signs, the RLO was considered to be the probable cause of the high mortality. Both VLP and MLP occurred at low prevalences and were considered secondary infections. The RLO was 0.22 to $0.35 \mu \mathrm{m}$ in diameter, granular or clavate, bounded by a cell wall and membrane, and possessed no nucleus but a nucleoid was present. When dividing, RLOs occurred in irregular shapes, such as dumbbells, awls, and crescents. The RLOs exhibited a predilection for muscle and connective tissues and were probably transported to various tissues and organs by hemocytes.
\end{abstract}

KEY WORDS: Eriocheir sinensis - Rickettsia-like organism · RLO - Ultrastructure · Pathology - Tremor disease - Epizootic

Resale or republication not permitted without written consent of the publisher

Pathogenic diseases caused by rickettsia-like organisms (RLOs) are rare in marine crabs, and have only been reported from Carcinus mediterraneus (Bonami \& Pappalardo 1980), Paralithodes platypus (Johnson 1984) and lithodes aequispina (Meyers et al. 1990). Although observed in freshwater amphipoda (Frederici et al. 1974) and redclaw freshwater crayfish (Owen et al. 1992), none have been reported from freshwater crabs. We report pathogenic infections of RLOs in the freshwater Chinese mitten crab Eriocheir sinensis causing mortality (about 30 to $90 \%$ ) and heavy losses of cultured crabs in recent years in southeast China. The disease first appeared in 1994 and spread quickly

*E-mail: wenwang@njnu.edu.cn in Jiangsu, Anhui, and Zhejiang provinces in southeast China. By 1998, the disease had spread to most aquaculture facilities of mitten crabs in China. Random samplings in Anhui Province in 1998 revealed that prevalence was $34.3 \%$ (Wei 1999). Seasonal occurrence of disease was correlated with high water temperatures $\left(19\right.$ to $\left.28^{\circ} \mathrm{C}\right)$ between July and August. Infected crabs were typically lethargic with loss of appetite and paroxysmal tremors of the pereiopod, hence the term 'tremor disease' given by the local fishermen. Infected crabs exhibited signs of weakness, anorexia, paroxysmal intense tremors and death in succession. During epizootics, the disease spread quickly, was difficult to control, and caused heavy losses to the industry. The cytopathology, ultrastructure and basic morphology of this RLO are described in this article.

Materials and methods. From May to September 1999, diseased crabs, weighing 30 to $90 \mathrm{~g}$, with typical 'tremor disease' signs were taken from 6 affected ponds $\left(\mathrm{O}_{2}=5\right.$ to $7 \%$ and 19 to $\left.28^{\circ} \mathrm{C}\right)$ in the Sihong and Hongze districts, northern Jiangsu Province, China. Healthy crabs were taken from 2 unaffected ponds $\left(\mathrm{O}_{2}=7\right.$ to $8 \%$ and 20 to $\left.28^{\circ} \mathrm{C}\right)$ in Suzhou, southeastern Jiangsu Province. During the same period in 2000, samples were again taken from the same 8 ponds (water temperature and dissolved oxygen were roughly the same as in 1999). At the same time, diseased crabs were sampled from other districts: Luhe, Yixin and Gehu in Jiangsu Province, and Tianchang in Anhui Province. Crabs with signs of weakness or obvious tremor were dissected and sampled.

Blood smears of every crab were collected for Giemsa stainning before dissecting. Impression smears of hearts, gills, hepatopancreas, pereiopod muscles, thoracic ganglion and gonads from diseased and healthy crabs were also stained with Giemsa. The smears were fixed on film with $10 \%$ methanol, airdried then, placed directly in a glass Coplin jar con- 
taining Giemsa stain diluted 1:10 with $\mathrm{pH} 6.8$ phosphate buffer for $45 \mathrm{~min}$. The Giemsa stain was prepared using $5 \mathrm{ml}$ of Giemsa stock solution (Giemsa powder $0.7 \mathrm{~g}$, glycerol $50 \mathrm{ml}$ and methanol $50 \mathrm{ml}$ ) mixed with $100 \mathrm{ml}$ phosphate buffer $\mathrm{pH} 6.8$ and $5 \mathrm{ml}$ methanol (Du 1998). This method was also used for semi-thin section staining but modified by elongating staining time to $1.5 \mathrm{~h}$ and increasing the temperature to $60^{\circ} \mathrm{C}$. Inclusion bodies were identified in the smears of diseased crabs using an Olympus BH-2 microscope.

For light and electron microscopies, 1 to $2 \mathrm{~mm}^{3}$ portions of gill, guts, hepatopancreas, cardiac muscle, pereiopod muscle, thoracic ganglion and gonad were fixed in $4 \%$ glutaraldehyde in phosphate buffer for $4 \mathrm{~h}$ at $4^{\circ} \mathrm{C}$, washed for $2 \mathrm{~h}$ at $4^{\circ} \mathrm{C}$ in the same buffer, then postfixed in buffered $2 \%$ osmium tetroxide for $2 \mathrm{~h}$ at $4^{\circ} \mathrm{C}$. The tissues were dehydrated through a graded series of acetone and embedded in Epon 812. Semithin sections for light microscopy (LM) were stained with $1 \%$ methylene blue and Giemsa stain respectively. Ultrathin sections were double stained with uranyl acetate and lead citrate, and observed with a Hitachi H-600 transmission electron microscope (TEM).

Results. All of the 46 diseased crabs from affected ponds were infected varyingly by the RLO. One crab was infected by virus-like particles (VLP), and 6 were infected by a microsporidian-like protozoan (MLP). No parasite or disease agent was detected in 23 crabs examined from the 2 unaffected ponds.

From blood smears and tissue impression smears, inclusions that stained pink to bluish-purple with Giemsa were observed in the cytoplasm of small granular hemocytes (Fig. 2) and connective tissue (Fig. 1) of infected crabs. The percentage of the cell with inclu-
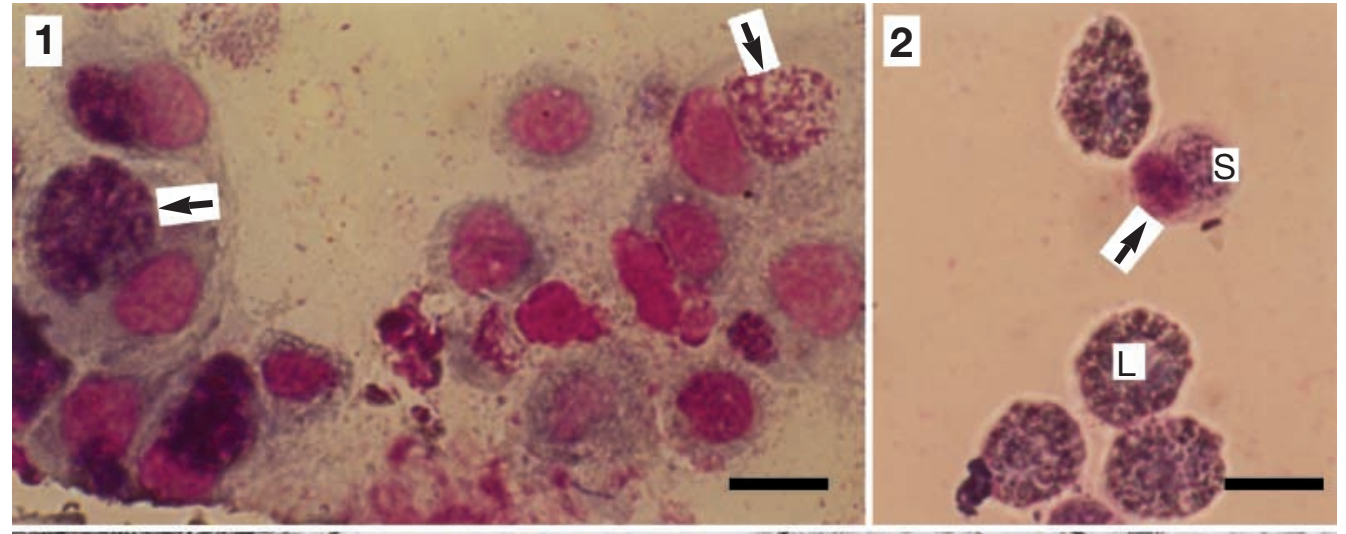
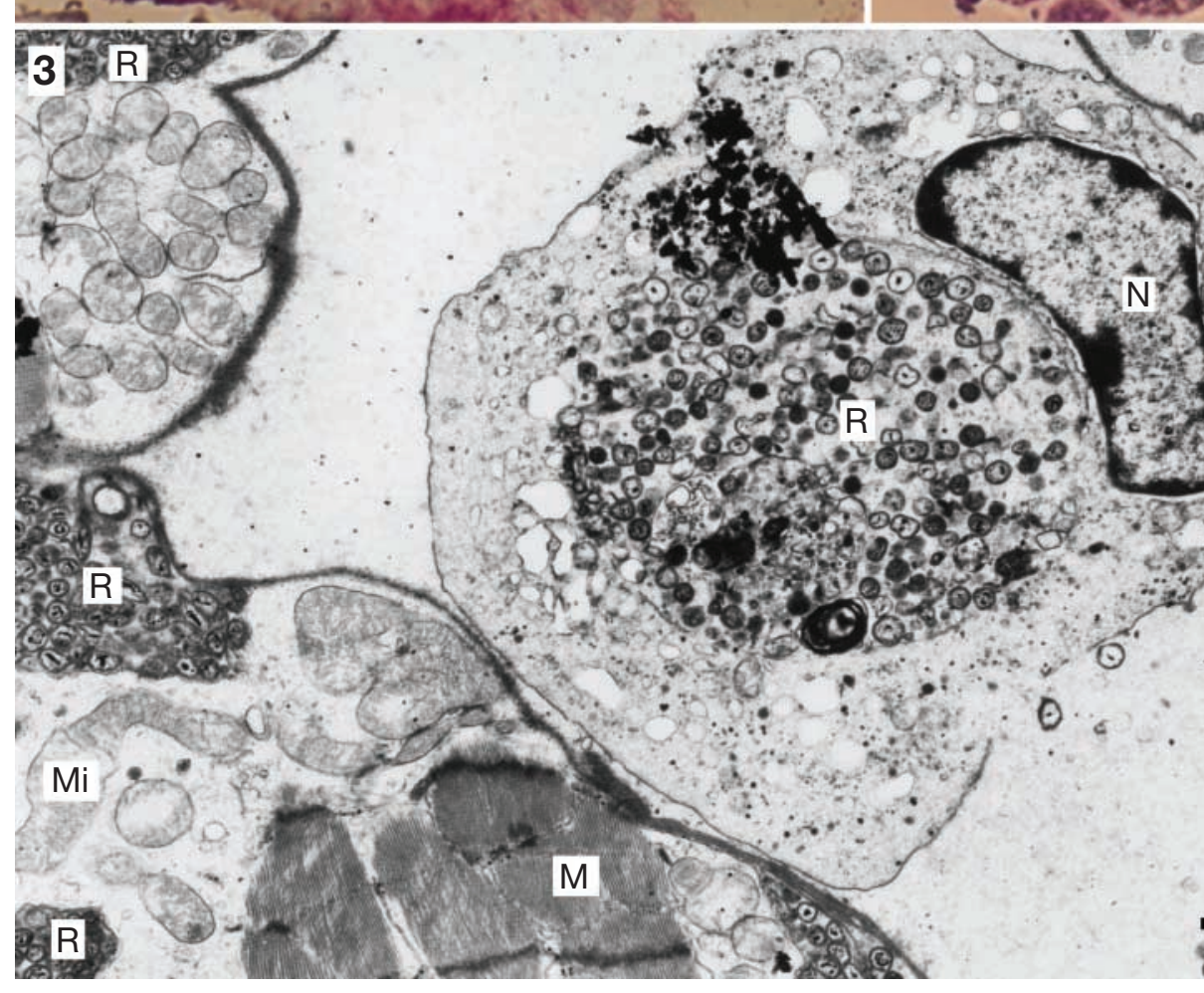

Figs. 1 to 3. Eriocheir sinensis. Fig. 1. Light micrograph of impression smears from the thoracic ganglion of an infected crab with a typical tremor. Rickettsia-like organism (RLO) colonies in the cytoplasm of connective cells stained pink to bluish-purple with Giemsa stain (arrows). Scale bar $=10 \mu \mathrm{m}$. Fig. 2. Light micrograph of a blood smear from infected crab stained with Giemsa. An RLO colony showing a pink color with Giemsa stain (arrow) can be seen inside a small granular hemocyte (S) from the hemolymph. The cells around it are large granular hemocytes (L). Scale bar $=10 \mu \mathrm{m}$. Fig. 3 . TEM micrograph of cardiac muscle tissue from an infected crab, showing large numbers of RLOs (R) within vacuoles of hemocytes and in muscle cells (M). The nucleus (N) of the host hemocyte is laterally compressed. (Mi) indicates mitochondria in the muscle cell. Scale bar $=1.5 \mu \mathrm{m}$ 
sions was about 20 to $40 \%$ in the smears from the crabs with signs of weakness and 50 to $80 \%$ in smears from crabs with signs of obvious tremor. There was a small difference in the color of inclusions in smears of hemocytes and impression smears of tissues. The former were pink while the latter were more bluish-purple.
Observations by TEM revealed that the Giemsapositive inclusions were microcolonies of a RLO within membrane-bounded vacuoles (Fig. 3). The RLO had a prokaryote character, with no nucleus but contained a nucleoid (Fig. 4). The internal structure had an electron-dense center, with filiform structures around it.

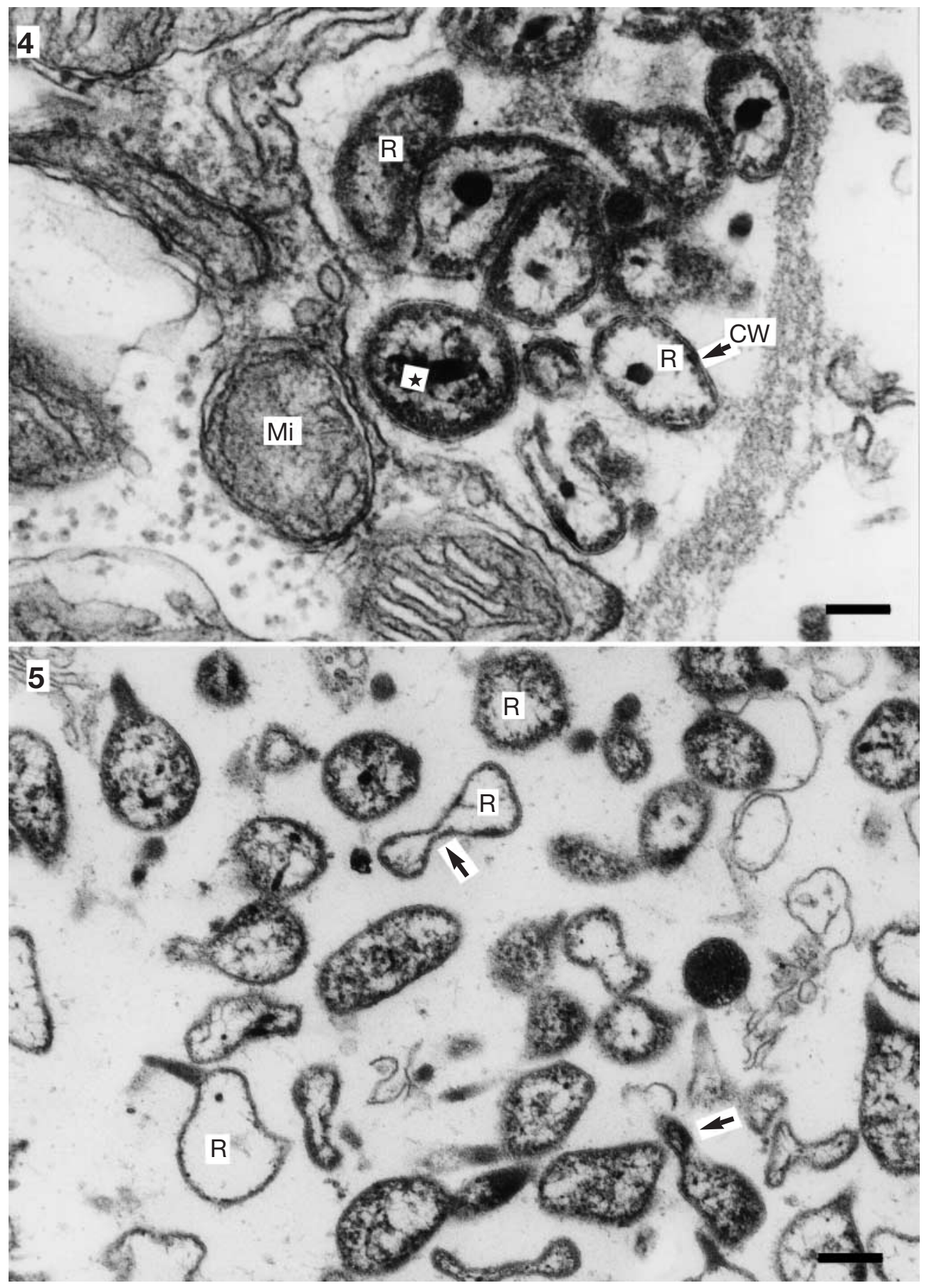

Figs. 4 \& 5. Eriocheir sinensis. Fig. 4. TEM micrograph of pereiopod muscle from an infected crab at high magnification showing the fine structure of RLO (R), the cell wall $(C W)$ and the nuclear area ( $\star$ ). Mi: mitochondria. Scale bar $=170 \mathrm{~nm}$. Fig. 5. TEM micrograph of a hemocyte from an infected crab showing electron-lucent RLOs (R) with irregular shapes, budding and binary fission (arrows). 
The RLOs varied in size between 0.22 and $0.35 \mu \mathrm{m}$ in diameter when in rounded form and $0.2 \times 0.9 \mu \mathrm{m}$ when bacilliform. Without exception, the RLOs were located in muscle and connective tissues within the gonad, the pereiopods, midgut, hepatopancreas nerves, heart (Fig. 3), and gills of moribund crabs.

Two forms of RLO were often detected in the hemocytes. One was electron-dense and spherical-shaped (Fig. 4); the other was electron-lucent irregular-shaped with budding and binary fission (Fig. 5). Many RLOs were contained in membrane-bound vacuoles in hemocytes (Fig. 3). When dividing, RLOs were irregular in shape, resembling dumbbells, awls, or crescents (Fig. 5). When mature, they were apparantly released by the rupture of the host cell.

In all diseased crabs, RLO colonies were observed inside hemocytes (Fig. 2). Giemsa staining showed that the percentage of hemocytes that possessed RLO inclusions increased with the severity of disease. Ultrastructure revealed that RLO were mainly distributed in the connective tissues of heart and guts from crabs with signs of weakness, and could be detected additionally in nerves and muscles from crabs with signs of obvious tremor. RLOs were likely carried to other tissues and organs by infected hemocytes.

In the body muscle tissues from crabs with tremor, the occurrence of RLO was similar to that in cardiac and gut muscle cells. Most RLOs were in the connective tissue capsule, the cytoplasm of pereiopod muscle cells, and in connections between nerves and muscle cells (myoneural junctions). In muscle cells, RLOs were dispersed in twos or threes in the sarcoplasmic reticulum. In the digestive system, RLOs were mainly present in the connective tissues underlying the epithelial cells and muscular layer. RLOs were also present in neurogliocytes of the thoracic ganglion.

VLPs were found in the gill epithelium of 1 moribund crab also infected by RLOs. The crab was collected from the Sihong district. VLPs were not detected in other tissues of the crab or in other moribund crabs. The VLP was spherical, $100 \mathrm{~nm}$ in diameter, and could form an inclusion body in the cytoplasm. An MLP was found only in the hepatopancreas of 6 moribund crabs that were also infected by RLOs. All the microsporidian-infected crabs came from only 1 pond in Sihong district and they were found in both years of sampling. Certain characteristics, such as the lack of a parasitophorous vacuole, the lack of distinct numbers of spores occuring in spore packets, and the small size (1.0 to $1.2 \mu \mathrm{m})$, suggested that the microsporidian might be a member of the genus Ameson.

Discussion. The etiological agent of 'tremor disease' in Eriocheir sinensis appeared to be a RLO that was always present in diseased crabs. By contrast, VLPs and an MLP were found only occasionally and were not considered to be involved in the etiology of the disease because of their low prevalences and sites of infection. We consider the VLP and MLP as secondary invaders that infected crabs weakened by infection with RLOs.

RLOs were observed systemically in Eriocheir sinensis and the resulting histopathology might explain the gross signs of the disease. RLO infection of the musculature and connective tissue of pereiopods, heart and guts could have been the cause of weakness and anorexia. RLOs in the thoracic ganglion (Fig.1) and myoneural junctions could have affected nerve transmission leading to paroxymal tremor of the pereiopods.

There are few reports of pathogenic RLOs causing serious diseases in crustaceans (Vago et al. 1970, Frederici et al. 1974, Lightner et al. 1985, Brock et al. 1986, Owens et al. 1992), and even fewer have been reported from crabs. Mass mortality of shrimp has been associated with RLOs (Krol et al. 1991, Lightner et al. 1992, Loy \& Frelier 1996), and infections in blue king crabs Paralithodes platypus (Johnson 1984, Meyers et al. 1990), golden king crabs Lithodes aequispina (Meyers et al. 1990), and green shore crabs Carcinus mediterraneus (Bonami \& Pappalardo 1980) were thought to be fatal. Prevalences from aquaculture systems have rarely been reported. In blue crabs Callinectes sapidus, the prevalence of RLO was $2.3 \%$ in a Maryland shedding facility, but heavy infections were not fatal (Messick \& Kennedy 1990), and were associated with little pathology (Messick 1998). However, the infection in the Chinese mitten crab is significant due to the high prevalence in pond systems and the rapid mortality associated with the disease. These conditions are similar to those reported for epizootics in shrimp aquaculture systems (Frelier et al. 1993).

The morphological descriptions of RLOs in crustaceans are varied. As in tremor disease, they mostly infect connective tissues and hemolymph. Unlike the RLO reported by Johnson (1984), Bower et al. (1996), Messick (1998), Brett \& Prior (1999) and Drobne et al. (1999), we did not find RLOs in the epithelium of the hepatopancreas although they were found in the underlying connective tissues. Our cytopathological study revealed that RLOs only infected hemocytes, muscle, and connective tissues but not epithelial cells. Like the RLO in redclaw crayfish (Romero et al. 2000), we also found RLO colonies inside small granular hemocytes of the hemolymph (Fig. 2).

The morphology of RLOs in the mitten crab had typical characteristics of rickettsias. Characteristics such as transverse binary division in cytophagous vacuolus (Fig. 5), formation of inclusion bodies (Figs. 1 to 3) or single appearance in the cytoplasm, and inhibition of phagosome-lysosome fusion, suggested that this RLO may be a member of the genus Ehrlichia (Wen 1999). 
However, further studies on immunology and molecular biology (Tan \& Owens 2000) will be needed to determine its relationship to other RLOs.

Although the RLOs had electron-dense and electronlucent forms (Fig. 5), they differed from those of Chlamydia-like organisms (CLOs). The condensed forms and elementary bodies of CLOs are usually devoid of organelles except the nuclear area (Sparks et al. 1985), whereas the electron-dense forms of our RLO were ribosome-rich in the periphery of the body. In addition, the reticulate (initial), intermediate and ellipsoidal bodies of CLOs are less densely packed, contain more cytoplasmic organelles and are larger than the elementary bodies (Sparks et al. 1985). By contrast, the electron-lucent forms of our RLOs lacked ribosomes and they were similar in size to the electrondense forms, not 6 times larger. Another difference between CLOs and RLOs is that CLOs are commonly spherical or oval and never bacilliform as some of the RLOs described here.

Acknowledgements. We thank Dr. Jeffery Shields for his critical review of the manuscript. Mr. Xu Zaikuan helped sample crabs in commercial growout ponds, and Mr. Du Kaihe provided technical assistance for electron microscopy. This study was partially funded by the Natural Sciences Research Foundation of Science and Technique Office in Jiangsu Province (No.BL2000305) and the Three-project for Aquaculture in Jiangsu Province (No.Z200101).

\section{LITERATURE CITED}

Bonami JR, Pappalardo R (1980) Rickettsial infection in marine crustacea. Experientia 36:180-181

Bower SM, Meyer GR, Boutillier JA (1996) Stained prawn disease (SPD) of Pandalus platyceros in British Columbia, Canada, caused by a rickettsial infection. Dis Aquat Org 24:41-54

Brett FE, Prior HC (1999) Description of a hepatopancreatic rickettsia-like organism in the redclaw crayfish Cherx quadricarinatus. Dis Aquat Org 36:77-80

Brock JA, Nakagawa LK, Hayashi T, Teruya S, Van Campen $\mathrm{H}$ (1986) Hepatopancreatic rickettsial infection of the penaeid shrimp, Penaeus marginatus (Randall), from Hawaii. J Fish Dis 9:73-77

Drobne D, Trus J, Nidari N, Zidar P (1999) Morphological description of bacterial infection of digestive glands in the terrestrial isopod Porcellio scaber (Isopoda, Crustacea). J Invertebr Pathol 73:113-119

Du ZM (1998) Practical techniques for histology, 2nd edn. Peoples Hygienic Press, Beijing, p 94-98 (in Chinese)

Federici BA, Hazard EI, Anthony DW (1974) Rickettsia-like organism causing disease in a crangonid amphipod from

Editorial responsibility: Timothy Flegel,

Bangkok, Thailand
Florida. Appl Microbiol 28:885-886

Frelier PF, Loy JK, Kruppenbach B (1993) Transmission of necrotizing hepatopancreatitis in Penaeus vannamei. J Invertebr Pathol 61:44-48

Johnson PT (1984) A rickettsia of the blue king crab Paralithodes platypus. J Invertebr Pathol 44:112-113

Krol RM, Hawkins WE, Overstreet RM (1991) Rickettsial and mollicute infections in hepatopancreatic cells, of cultured Pacific white shrimp (Penaeus vannamei). J Inverteb Pathol 57:362-370

Lightner DV, Redman RM, Williams RR, Mohoney LL and 3 others (1985) Resent advances in penaeid virus disease investigations. J World Maricult Soc 16:267-274

Lightner DV, Redman RM, Bonami JR (1992) Morphological evidence for a single bacterial etiology in Texas necrotizing hepatopancreatitis in Penaeus vannamei (Crustacea: Decapoda). Dis Aquat Org 13:235-239

Loy JK, Frelier PF (1996) Specific nonradioactive detection of the NHP bacterium in Penaeus vannamei by in situ hybridization. J Vet Diagnos Invest 8:324-431

Messick GA (1998) Diseases, parasites, and symbionts of blue crabs (Callinectes sapidus) dredged from Chesapeake Bay. J Crustac Biol 18:533-548

Messick GA, Kennedy VS (1990) Putative bacterial and viral infections in blue crabs, Callinectes sapidus Rathbun, 1896 held in a flow-through or a re-circulation system. J Shellfish Res 9:33-40

Meyers TR, Shorts, Eaton W (1990) Diseases of five commercial crab species in southeast Alaska. In: Perkins FO, Cheng TC (eds) Patholgy in marine science. Academic Press, New York, p 407-420

Owens L, Muir P, Sutton D, Wingfield M (1992) The pathology of micrbial diseases in tropical Australian Crustacea. In: Sharff M, Subasinghe RP, Arthur JR (eds) Diseases in Asian aquaculture 1. Fish Health Section, Asian Fisheries Society, Manila, p 165-172

Romero X, Turnbull JF, Jiménez R (2000) Ultrastructure and cytopathology of a Rickettsia-like organism causing systemic infection in the redclaw crayfish, Cherax quadricarinatus (Crustacea: Decapoda), in Ecuador. J Invertebr Pathol 76:95-104

Sparks AK, Morado JF, Hawkes JW (1985) A systemic microbial disease in the Dungeness crab, Cancer magister, caused by a Chlamydia-like organism. J Invertebr Pathol 45:204-217

Tan CK, Owens L (2000) Infectivity, transmission and 16S rRNA sequencing of a rickettsia, Coxiella cheraxi sp. nov., from the freshwater crayfish Cherax quadricarinatus. Dis Aquat Org 41:115-122

Vago C, Meynadier G, Juchault P, Legrand J, Amargier A, Duthoit J (1970) Une maladie rickettsienne chez les Crustaces Isopodes. CR Acad Sci Paris, (Ser D) 271: 2061-2063

Wei ZN (1999) An investigation on the epidemiology of tremor disease of the Chinese mitten crab, Eriocheir sinensis. Freshw Fish 7:16-71 (in Chinese)

Wen BH (1999) Ehrlichia and ehrlichiosis. In: Yu SR, Chen XR (eds) Rickettsiae and rickettiosis. Military Medical Sciences Press, Beijing, p 142-150 (in Chinese)

Submitted: April 10, 2001; Accepted: November 1, 2001

Proofs received from author(s): February 18, 2002 